\title{
MUJER Y CAMBIO SOCIAL EN EL MEDIO RURAL GALLEGO
}

\author{
por \\ SUSANA de la GALA GONZÁLEZ
}

Cualquier interpretación antropológica es válida con tal que se atenga a los testimonios en los que se basa. Clifford Geertz expresa esta misma idea cuando dice: "la cultura de un pueblo es un conjunto de textos... que el antropólogo se esfuerza por leer por encima del hombro de aquellos a quienes dichos textos pertenecen propiamente" $(1988,372)$. La que voy a realizar aquí está avalada por los textos. Lo único que creo que he incorporado a ellos es la clave que la convivencia y estos mismos textos me proporcionaron para interpretarlos. El resultado se verá a medida que avancemos.

El ámbito social más amplio en una comunidad campesina es el municipio. Le siguen la parroquia y la familia. El orden que sigo en estas páginas es justo el inverso; comencé analizando la posición y el prestigio concedidos por la familia a la mujer, seguí con el análisis de los juicios sociocéntricos que miran hacia dentro y hacia fuera de la parroquia y que determinaron un sistema de casamientos vigente hasta hace muy poco en el municipio orensano de Viana do Bolo, e intenté, finalmente, confirmar el menor valor social concedido a la mujer en esta zona respecto al concedido al hombre y a la unidad doméstica (no a la casa-edificio), tal como me permitió colegir el análisis precedente del papel de la mujer en el sistema de casamientos mediante el análisis de los rituales que se pueden observar hoy en día, apenas sin cambio en la vida cotidiana y de un "rito de

"CUADERNOS DE ESTUDIOS GALLEGOS", Tomo XXXIX, Fascículo 104, Santiago 1991. 
inversión de status" que se celebró hasta hace algún tiempo en el "antroido" o "entrudio" de esta zona. Termino haciendo una breve referencia a la vigencia y permanencia de la ideología masculina dominante en la actualidad y a la importante función de la mujer en la cultura, la socialización de sus hijos, que tanto contribuye a que no haya perdido vigencia ésta. Adelanto que la socialización y las otras mediaciones que lleva a cabo la mujer entre la "naturaleza" y la "cultura" la condenan a una inferior posición respecto al hombre en la sociedad.

\section{La organización familiar y la mujer}

El tipo de residencia post-matrimonial más frecuente en la comarca orensana de Viana do Bolo fue, hasta hace muy poco, la natolocal, que respondía a la necesidad de seguir viviendo con los padres respectivos cuando los esposos no podían comprar, alquilar o heredar casa donde poder vivir independienteménte de éstos y tierras que trabajar. La norma ideal que expresa el refrán "o casado casa quer e quen non a ten tena que facer" era, sin embargo, la autonomía del matrimonio, cuya menor frecuencia justifican los actores sociales porque "no había medios pa poder vivir, no había casa pa poder vivir". La alternativa a estos dos tipos de residencia post-matrimonial era que uno de los esposos se fuera a residir con los padres del otro, que frecuentemente era motivo de conflictos internos y que tampoco parece haber tenido gran implantación. Me propongo descubrir los motivos de la mayor frecuencia del primer tipo a pesar de la contradicción patente entre la práctica habitual y la norma ideal, los motivos del fuerte rechazo expresado por los testimonios hacia el tercer tipo, y la consideración que merecían la mujer en cada uno de ellos, la consideración que le atribuía la ideología masculina dominante.

Si la contribución de la mujer casada que residía nato-localmente a la subsistencia familiar (el cultivo de las tierras y algún trabajo remunerado inferiormente al del varón) era idéntica a la de la mujer soltera y recibía la misma e igualmente inferior consideración que la contribución del varón, ¿por qué prolongar a veces esta situación algunos años después de la muerte de los padres, una vez que la herencia había sido repartida (puesto que en esta zona no hay mejora ni cesión en vida de los padres de la parte equitativa de la herencia que corresponde a cada hijo)? Lisón Tolosana explica este hecho por la mayor cohesión interna de la familia de orientación respecto de la familia de procreación $(1979,320)$, como comprenderemos fácilmente si tenemos en cuenta los testimonios que dicen de los maridos que eran "muy duros, muy malos con las mujeres" cuando los esposos adoptaban residencia neolocal y de las relaciones nuera-suegra y yerno-nuera que eran generalmente difíciles, lo que explica a su vez que fueran evitadas ("tratar ca nora malo, tratar co xenro pior"). Parece, por

"CUADERNOS DE ESTUDIOS GALLEGOS", Tomo XXXIX, Fascículo 104, Santiago 1991 
tanto, que la residencia natolocal habría de beneficiar a la mujer, por cuanto le evitaba el maltrato por parte del varón, y a la unidad doméstica de ambos cónyuges, por cuanto aseguraba un nivel semejante de producción al anterior al matrimonio de los que residían natolocalmente y evitaba relaciones conflictivas en el seno de la familia por introducir en ella un nuevo miembro, como vamos a ver ahora.

Si el nuevo miembro de la unidad doméstica era la mujer, la casaedificio se convertía, como dice Lourdes Méndez, en un "terreno de lucha" $(1988,208)$ entre ella, su suegra y su cuñada (de la que el refrán dice, un poco ambiguamente, que solía ser mala con la esposa de su hermano, aunque también indica que la animadversión entre ellas solía ser recíproca: "as cuñadas nunca foron boas"); pero si el nuevo miembro de la unidad doméstica era el hombre, las relaciones podía llegar a ser extremadamente tensas, como indica el término "tratar" en el refrán insertado un poco más arriba, que es el utilizado para designar el difícil acuerdo monetario al que tienen que llegar el vendedor y el comprador del ganado que se lleva a la feria.

Pasemos ahora a la determinación de la posición que le corresponde y que le es asignada a la mujer en cada uno de estos tipos de residencia mediante el análisis de la petición de mano y de la ceremonia nupcial respectivas. Cuando los cónyuges iban a adoptar residencia natolocal, el padre de la novia apenas mostraba resistencia a darla en matrimonio (puesto que iba a permanecer dentro de la casa paterna) y tan sólo indicaba al novio que "vos veredes o que facedes, eu non teño" o que "non teño qué darlle, tu te arreglarás", como queriendo hacer referencia a que no podía dar a la hija dote; mientras que cuando los cónyuges iban a vivir en casa del varón ésta era pactada durante la petición de mano, que se desarrollaba más o menos de este modo:

"Llegada la ocasión, se presentaba el novio y su acompañante en la casa de la novia,... Saludan dando "as boas noites"... El pretendiente expone sus deseos, en tanto que la novia agacha la cabeza y hace que se pone triste ,... El padre protesta por el matrimonio diciendo que es muy pronto para que su hija se case, y después de algún diálogo la moza manifiesta que si no la dejan casar que se marcha con el novio o que se mata.. El padre, al oirlo, se pone furioso y replica que con mil demonios que se case, que no quiere ver más a la hija en casa, que busquen los padrinos y que el no se entere de nada" (N. Tenorio, 1984, 267).

Como podemos ver por la descripción del juez sevillano Nicolás Tenorio, esta petición es mucho más ritualizada que la anterior, el padre de la novia manifiesta resistencia a que su hija se case, como si ésta tuviese algún valor, y no tiene más remedio que dejarse convencer por los argumentos de su hija, que toma parte en la discusión; finalmente, "después 
de algún diálogo", se fija la dote, que expresará tanto el valor de la novia como el del novio (por eso se dice que los ricos se casaban entre sí): el de la novia porque el padre ha de poder pagarla y el del novio porque ha de estar de acuerdo con el status de su unidad doméstica, que tampoco sucedía en el caso anterior. La menor ritualización de la ceremonia nupcial en el caso de que los novios fuesen a adoptar residencia natolocal (se celebraba de noche y sin invitados) que en el caso de pensar ir a vivir a la casa del varón (pues se hacía un gran banquete, que terminaba con baile, y tornaboda), parece estar apuntando también en la dirección del menor valor concedido a la mujer en el primer tipo de residencia postmatrimonial, y a las unidades domésticas respectivas de los cónyuges, que los necesitaban para seguir manteniendo un nivel de producción adecuado al número de miembros de éstas y demostraban así indirectamente su dependencia, su pobreza y su inferior prestigio social. ¿Prefería entonces la mujer permanecer sometida a sus padres que vivir en casa de su marido o que vivir independientemente de los padres respectivos?

Desde el punto de vista de la ideología masculina y de la norma ideal expresada por el refrán, el valor de la mujer era mayor cuanto mayor fuera la cuantía de la dote, es decir, el valor social de la mujer está en función del valor social de su unidad doméstica y del varón que ocupa la posición superior dentro de ella,el padre; por otra parte, que la mujer se fuera a vivir a la casa de su marido suponía para ella estar sometida a su suegra y a su suegro, que detentaría el poder que le da ser padre de su esposo, además de estar sometida a éste. Si la mujer no recibía dote y tenía oportunidad de casarse, la residencia natolocal adelantaba la fecha del matriomonio respecto a la que determinaría la muerte de sus padres y el reparto de la herencia, y le evitaba tan complicada red de dependencia como la que acabo de describir para el caso de ir a vivir con los padres de su esposo, aunque disminuyera su valor social (que de todos modos era inferior, ya que el valor social de la mujer, dije antes, está en función del valor social de la unidad doméstica, y ésta la necesitaba para sobrevivir o para mantener su nivel de producción). De ahí que resulta lógico, desde el punto de vista de la mujer, que prefiriera este tipo de residencia a cualquiera de las otras dos, una la que acabo de analizar y otra la neolocal, que suponía una elevada posibilidad de maltrato por parte del varón.

Voy a examinar a continuación un ámbito más amplio que el de la unidad doméstica y unas relaciones sociales más complejas que las del matrimonio endógamo (dentro de la misma parroquia), así como los juicios (sociocéntricos) que determinan el sistema de casamientos vigente hasta hace muy poco en esta zona y el papel que representa la mujer en la sociedad. En las relaciones interparroquiales y en la ideología que expresan 
estos juicios (masculina) se determinan las posibilidades matrimoniales entre las parroquias del municipio y comarca de Viana do Bolo.

\section{El sistema de casamientos y la mujer}

Los juicios sociocéntricos que van a ser examinados aquí expresan únicamente el punto de vista de los habitantes de una parroquia, Mourisca, del municipio orensano de Viana do Bolo. El sistema de casamientos del que estos juicios hablan permanecería idéntico en el caso de que fueran los vecinos de otra parroquia quienes los formularan.

Viana es la villa y capital del municipio homónimo. "De Viana xa non queda ninguén, todos son dos pobos de por ahí"; efectivamente, los actuales habitantes del centro comercial de toda la comarca — al cual acuden para vender y comprar ganado, productos hortofrutícolas, etc.- proceden de los pueblos que empezaron a quedarse despoblados con las sucesivas oleadas de emigrantes y que ahora prácticamente lo están. Fueron "pobres" que montaron sus negocios, ganaron dinero y adquirieron tierras, para las que necesitaban quién las trabajara, nuevas oleadas de "pobres" que fueron primero "criados", después "caseiros" y finalmente "amos" de otros "criados" y así sucesivamente (aunque no en todos los casos). Su origen y la conceptualización tradicional de los "ricos" habrían bastado para motivar juicios como los que voy a mencionar enseguida, pero es que además estos "ricos" empleaban a mujeres de "criadas" o "hilanderas", que trataban a sus hijos de "señoritos" (y este es uno de los términos que utilizan aún ahora para referirse,en general, a los de Viana), y a hombres de "jornaleros" o "criados", relación de dependencia que tal vez no quisieran acentuar las primeras y los segundos casándose con ellos. A pesar de que se dice que eran "canallas", que iban a las fiestas "sólo de parranda, no bailaban" y que "las manejaban y después las dejaban", motivos que aducen las mujeres para justificar que consideraran poco deseable casarse con los jóvenes de la villa, se registraron al menos 5 bodas entre mujeres de Mourisca y hombres de Viana en los 110 años que examiné en los libros de parroquia de Mourisca; matrimonios de hombres de Mourisca y mujeres de Viana, sin embargo, no pude encontrar ninguno en los 50 años que estudié en un muestreo en el registro civil de la capital del municipio (1884-1936), quizás porque a los primeros hubiera resultado insoportable semejante demostración de dependencia, y poco probable el casamiento.

Las relaciones asimétricas entre los habitantes de los pueblos denominados "os da montaña" (Sever, Paradela, Rubiales, Penouta y Cepedelo), que contrataban "jornaleros" para segar su abundante cosecha de centeno (justificado por ser "casas todas de viejos", es decir, casas cuyos hijos habían emigrado), y los pueblos próximos, entre ellos Mourisca, tal vez 
fuera también el motivo de que los primeros fueran, despectivamente, denominados "medio taburelos da montaña" y de que las mujeres de Mourisca digan que no iban a sus fiestas porque "quedaban moi lonxe", junto con el hecho, que puede estar metafóricamente expresado por esta distancia afectiva, de que "os da montaña" vendieran con frecuencia parte del ganado que necesitaban para trabajar sus tierras cual si de "tratantes" se tratasen, actividad que los alejaba del estereotipo de "labrador" que las mujeres de Mourisca tienen en sus mentes y han interiorizado como estereotipo del marido deseable.

Algo parecido les sucedía con los habitantes de los pueblos denominados "os de indo pá Rua" (Lentellais, As Ermitas y Portomourisco), considerados "pobrísimos" ("esos pueblos eran pobrísimos, no tenían más que vino, vino y huertas, que regaban con calderos, por eso eran pobres, porque eran muy secos") y vendedores ambulantes, pues a veces tenían que recorrer $50 \mathrm{~km}$. con sus productos, pescado y cacharros, a hombros o al lomo de una mula para venderlos, que los alejaba también del prototipo del "labrador" (y más cuando a veces tenían que cambiarlos por centeno, alimento necesario en aquellos tiempos, del que carecían, que confirma la pobreza extrema que les atribuyen). Apenas hubo matrimonios de mujeres de Mourisca con hombres de estos pueblos, quizás para no descender a tan baja posición en la jerarquía social interparroquial como la que estos juicios reflejan, y tampoco a la inversa.

Los hombres del vecino San Mamed son considerados "sinvergüenzas" ("si pierden insultan y si pueden roban"), "mercantilistas", "mercaderes", "tramposos" y "negociantes" por vender sus productos ambulantemente, como los de los pueblos que acabamos de ver, y por sacar siempre beneficio (no lo necesitaban hacer por necesitar centeno para dar de comer a sus familias, como los anteriores), por vender sus productos por un precio superior al que pagaron por ellos; quizás por este motivo se alejen también lo suficiente del estereotipo del "labrador" como para registrarse tan sólo dos matrimonios en los 110 años que estudié en los libros de parroquia de Mourisca entre hombres de San Mamed y mujeres de ésta, y a la inversa ninguno en los 50 años estudiados en en muestreo anteriormente mencionado (pues en los libros de casamientos de la parroquia de Mourisca, sólo se registran los de sus mujeres).

Finalmente, las mujeres de Mourisca se casaron preferentemente con los hombres del vecino Fornelos de Coba, hacia los que sólo reputan ser "gritois", que eran "pobres", y los hombres de Mourisca se casaron preferentemente con las mujeres del vecino Tabazoa de Edroso, al que acudían para segar centeno y cortar leña; mientras que a la inversa apenas se registraron matrimonios, quizás porque los hombres de este pueblo eran considerados "borrachos", estos dos pueblos mantenían con Mourisca 
relaciones equilibradas y no de dependencia, otro posible motivo de que se registraran intercambios equilibrados de consortes entre ellos.

Del análisis precedente se pueden extraer las siguientes conclusiones:

1) El valor social y matrimonial de los individuos de un pueblo no depende únicamente del prestigio de la casa a la que pertenece, sino también del prestigio del pueblo al que pertenecen.

2) Las mujeres reflejaban fielmente en sus juicios los criterios por los que se rige la jerarquía social local, incluso más fielmente que los hombres, prestando así un gran servicio a la ideología masculina que subyace a ellos, pues el prestigio de una casa depende del de sus miembros varones y el de una mujer del de ellos.

3) Estos juicios sociocéntricos determinan el tipo de cónyuge deseable para los jóvenes de la parroquia de Mourisca, influyen en el tipo de matrimonio más frecuente (equilibrado, entre hombres y mujeres de posición social semejante) y expresan a su vez la jerarquía social local que está en su base.

4) Finalmente, la endogamia de pueblo fue siempre muy elevada en este pueblo, por lo que podemos hablar, con Lisón Tolosana, de la "unidad moral de la parroquia" que se manifiesta en costumbres como la compensación simbólica exigida al novio foráneo ("o piso", un convite) cuando corteja a una joven de ella. Esto último permite considerar a las mujeres "categoría de intercambio" en el sentido levi-straussiano y en esta dirección apunta la cita de Lisón Tolosana en relación a este hecho:

"¿Qué es lo que primaria y radicalmente puede alterar la balanza de la estabilidad y permanencia parroquial? La salida de sus mujeres jóvenes. De aquí las luchas por las mozas, la ritualización —sólo se ritualiza lo que es fundamental en una cultura- del paso de los límites parroquiales de la mujer, la compensación exigida por su pérdida, el principio teórico subyaciente de que por cada mujer que sale ha de entrar otra en la parroquia" $(1979,76)$.

De ritos y actividades ritualizadas voy a hablar a continuación. Buscaré a través de la metáfora subyaciente al concepto sociológico "superioridad" las pruebas de la superioridad del hombre en esta sociedad y análogamente respecto al concepto sociológico "inferioridad" y a la inferioridad de la mujer.

\section{La posición de la mujer en los rituales de la vida coti- diana \\ La matanza y la "malla" son dos actividades relacionadas con el ciclo agrícola de gran importancia para la subsistencia familiar, pues proporcio- nan reserva cárnica y de cereal para la elaboración del pan y la alimenta- ción del ganado. La forma en la que se realizan ha permanecido invariable}


hasta la actualidad, en la que se han incorporado ciertos avances técnicos sin alterar la división sexual del trabajo tradicional.

En la matanza, los hombres fueron, en esta zona, los encargados de agarrar, matar, rasurar y finalmente partir el cerdo, mientras que las mujeres "amparaban" y lavaban las tripas, recogían la sangre que el cerdo suelta por la herida que los hombres le hicieron en la "gorxa" y preparaban con ella las "filloas de sangue". Partir y picar la carne destinada a "encher" los chorizos es una tarea que realizaban y realizan igualmente ambos, pero adobar y "remexer" la carne picada, así como "encher" las tripas con ella es tarea exclusivamente femenina. Quiero pararme un momento en la "limpieza" que estas tareas requieren y en quién sea encargado de realizarla antes de hablar de la forma en que son realizadas.

La "limpieza" es una condición "sine qua non" para que un animal inicialmente perteneciente a la "naturaleza", el cerdo, pueda ser utilizado como materia prima de alimentos tan fundamentales en la dieta campesina como son el chorizo, los jamones, los lacones, la "cachucha", la "soá", etc.; inicialmente, cuando el cerdo acaba de ser matado, son los hombres los encargados de realizarla ("rasurado", del que dicen "queda como jaspe, casi vale ya para comer"), pero para ellos no exige, como para las mujeres, manipular la "suciedad" de las tripas o la sangre, que ellas tienen que manipular quizás por la semejanza entre "lavar" la ropa y las tripas, por una parte, y la sangre menstrual y la del animal por otra. Si consideramos que la "limpieza" de la casa y de las transformaciones culinarias que tienen lugar en ella fue una tarea tradicionalmente femenina podemos comprender que los hombres son los encargados de "rasurar" el cerdo, por la importancia que tiene esta actividad para separar la "naturaleza" de la "cultura" en que convierten las reservas cárnicas que del cerdo se obtienen, y posibilitar así la transformación cultural quizás más decisiva para la supervivencia familiar. Si este hecho es puesto en conexión con la anterioridad y la verticalidad de las tareas masculinas en la matanza, frente a la posterioridad y posición inclinada necesaria para realizar las tareas femeninas, y reparamos en que "primero" y "arriba" son dos connotaciones del concepto "superior jerárquico", y que "posterior" y "abajo" son dos connotaciones del concepto "inferior jerárquico", vemos con claridad que, también por el hecho de que las tareas masculinas requieren "fuerza" y "saber" mientras para las femeninas no se necesita cualificación alguna, el hombre está representando simbólicamente mediante la anterioridad y verticalidad con que realiza sus tareas el rol "superior" de la jerarquía de prestigio local, y las mujeres el rol "inferior", que se corresponde con la menor cualificación que exigen las tareas femeninas y el menor prestigio concedido a ellas.

Pasemos a la "malla" del centeno en su forma tradicional de realizarla. Los hombres utilizaban tradicionalmente un instrumento (el "mallo") para

"CUADERNOS DE ESTUDIOS GALLEGOS", Tomo XXXIX, Fascículo 104, Santiago 1991. 
azotar la base de la espiga y desprender ésta de la "palla", que también recogían, mientras las mujeres "cribaban" el grano con un "cribo" o "zarando" y recogían separadamente, tras "barrer" el suelo de la "aira" o era, el grano y la espiga, que serviría para alimentar el ganado. La anterioridad y verticalidad de las tareas masculinas y la posterioridad y posición inclinada de las tareas femeninas, junto a la escasa cualificación necesaria para las segundas y el hecho de que no recibieran recompensa (la comida o "xantar" al que sólo eran invitados los hombres por el dueño del centeno "mallado"), está indicando como antes que las primeras reciben mayor prestigio que las segundas y que se están representando ritualmente, pues la forma de realizar la matanza y la "malla" está ritualizada desde antiguo, los roles del "superior" y del "inferior" respectivamente de la jerarquía local de prestigio social. Que esta no es únicamente una interpretación "etic" lo demuestran algunos testimonios recogidos, que hablan de "a ver si poden chegar arriba" refiriéndose a los jóvenes que estudian, y de los "ricos" como los que están arriba, y de su actitud con los "pobres" como "pisar" al que está abajo.

En el contexto del carnaval de la zona se puede observar también que la "fuerza" y el estar arriba son atributos del superior jerárquico, y que el que está abajo es siempre inferior, aún cuando la representación de estos roles sea llevada a cabo por actores, fenómeno al que Turner (1988) llama "ritos de inversión de status", de los que dice que la inversión es sólo aparente y que son una ocasión periódica de purificar la jerarquía social subyacente.

El domingo de "antroido" o "entrudio" se celebraba hasta hace muy poco en Viana la persecución y decapitación de los gallos comprados para la ocasión por quienes eran los encargados de realizar ambas, los niños en edad escolar. Con anterioridad habían sido elegidos en la escuela un niño y una niña como "rey" y "reina", respectivamente, que se situaban en sus balcones para contemplar la representación, y los encargados de llevarlos hasta esa fecha a hombros desde la escuela a sus casas (signo de sometimiento del inferior al superior). Llegado el día, todos los niños se juntaban en la plaza para "marear" primero y "decapitar" después al gallo que representa al superior jerárquico y que siempre denotó atributos viriles (la imagen del gallo en el corral dominando a la gallina y a los polluelos aparece en algunos refranes conocidos en la zona como representación del orden jerárquico en la familia tradicional), a todos los que han sido comprados para la ocasión, reservando el último para la "gallina ciega" (la madre, siguiendo con la imagen del gallo como varón y los polluelos como los hijos); los sucesivos niños se tapan los ojos con una tela o venda y blanden el arma cortante sobre el gallo enterrado hasta el cuello en un montón de tierra (mientras los otros habían sido colgados de las 
patas de cuerdas extendidas entre las dos aceras de la calle principal del pueblo). Pero hemos de observar que el "rey" y la "reina" que contemplan la representación desde el balcón pueden ser considerados fácilmente como los superiores que permiten excepcionalmente - Turner habla de "el acento puesto, en lugar de su supresión, en el principio de jerarquía (...), sin duda purificado por la inversión, un proceso gracias al cual se mantiene la vertebración estructural de la vida rural", (1988, 191-192)— la inversión de la jerarquía que supone que los inferiores (los niños) decapiten al superior (el gallo), sin perder por tanto su posición superior.

¿Qué implicaciones tiene esta interpretación para el tema que estamos examinando, la posición de la mujer en la sociedad como un todo campesina y el reconocimiento que le concede la ideología masculina, que adelanto que expresa el punto de vista de la "cultura", por las actividades domésticas, trabajos remunerados y tareas agrícolas que tiene que realizar en correspondencia con esta posición? La ambiguiedad simbólica que supone el que la mujer sea simbólicamente representada mediante la "reina" ("arriba") y mediante la "gallina ciega" ("abajo"), la inferioridad que denota su posición durante las tareas que realiza en la matanza y en la malla, la falta de prestigio que indica el hecho de que no necesite especial cualificación, de que manipule la "suciedad" y de que incluso no reciba compensación (el "xantar" al que no eran invitadas) y que es análoga a la falta de valor social que examinamos en el apartado 1 y en el apartado 2 , son algunas de las notas por las que Ortner define la "posición intermedia entre la cultura y la naturaleza" $(1979,119)$ de la mujer, que se corresponde con el "status secundario" que se le atribuye en la sociedad y que creo haber demostrado aquí para el caso concreto de la comarca orensana de Viana do Bolo.

¿Qué notas definen la "cultura" en relación a la "naturaleza" según Ortner? Una definición y una imagen tal vez lo aclaren. La "cultura" "está empeñada en generar y mantener - dice Ortner- sistemas de formas significativas... mediante los cuales la humanidad intenta ejercer su control sobre la naturaleza" (o.c., 128), entre ellos los signos y los símbolos lingüísticos y de todo tipo, y la tecnología, mediante la que este control se hace efectivo. El hecho de que la mujer ocupe una "posición intermedia entre la cultura y la naturaleza" por realizar la primera socialización de sus hijos y otras transformaciones culturales, como las culinarias y aquella señalada anteriormente de la "suciedad" en "limpieza", la acerca un poco más a la "naturaleza", necesitada de control, que a la "cultura" a la que tan fielmente sirve, y por supuesto en relación a la posición ideológicamente dominante que tienen los hombres dentro de ésta última (a lo que ayuda el que la reproducción de la especie sea biológicamente imposible para el varón); la imagen a la que me refería antes no es otra que la 
de "la cultura como un calvero en medio del bosque que constituye el medio natural más amplio. Desde este punto de vista, aquello que es intermedio entre la cultura y la naturaleza puede parecer situado tanto arriba como debajo (o al lado) de la cultura, pero está sencillamente fuera y alrededor" (o.c., 114). Como la cultura y la sociedad a la que ésta presta el servicio a veces de legitimar se solapan, la inferioridad ritual y el inferior prestigio concedido a las actividades, funciones y roles de la mujer en la familia y en la sociedad permiten hablar también de su inferior posición en el ritual, en la familia y en la sociedad, que son tres ámbitos analíticamente distinguibles dentro de la sociedad como un todo, y definidos por relaciones de diferente amplitud y de diferente representación simbólica.

En relación a la asociación de la mujer con la "naturaleza" que determina el que sea ella quien realice la mediación entre ésta y la "cultura" que supone socializar a los hijos, por ejemplo, y el que sea ella la biológicamente preparada para reproducir la especie, la necesidad que tiene la "cultura" de controlar la "naturaleza" si quiere obtener algún provecho de ella se traduce, en el caso de la mujer, en el control social de su conducta sexual (que ha de ser puesta al servicio de la comunidad, dentro del vínculo matrimonial) y en el rechazo de la ilegitimidad que pude constatar a través de los testimonios que recogí en la comarca de Viana do Bolo. Un refrán, "a muller e a ovella, con día na cortella", que los hombres interpretaron como "as ovellas hai que ir con elas, si no non volven; as mulleres antes non iban solas (ás festas), iban con eles (os homes), xuntábanse 10 ou 12 mozas i á volta o que tiña novia iba con ela hasta a mitade do camiño e despois xa volvía ela con todos ao pueblo", permite relacionar la "naturaleza" de la mujer con su necesidad de control; y un término, "naturales", utilizado hasta hace muy poco para referirse a los hijos ilegítimos, permite relacionar la censura moral y social de las madres solteras con el haber escapado al control que necesitan las mujeres: cuando son madres solteras convierten el hecho biológico de la reproducción y a su descendencia en mucho más "naturales" que cuando están casadas y se someten a dicho control. La elevada tasa de ilegitimidad registrada en esta zona hasta la década de los 50 tiene en los testimonios diversas explicaciones, algunas de ellas también ajustadas a esta interpretación, como cuando dicen que "el cariño era loco", e interpretan el refrán "o lume ó pé da estoupa, van o demo e a sopla" como "que 'a ocasión fai ó home ladrón', que a ocasión existe"; como si el acto sexual fuese un robo permitido por la mujer que se enciende, que no se controla, o cuando interpretan el refrán "besos non fan fillos, pero son ameazas" como "que son ameazas, que siempre hay algo más", como si a la mujer fuese extremadamente difícil prohibirle hacer al varón lo que él desea.

Para terminar, he de señalar que aunque ha sido considerable la in-

"CUADERNOS DE ESTUDIOS GALLEGOS", Tomo XXXIX, Fascículo 104, Santiago 1991. 
fluencia del cambio social experimentado en las últimas décadas en el medio rural y en esta zona sobre el prestigio social del hombre, que ha aumentado pese a la desvalorización reciente del trabajo agrícola en relación al trabajo en la ciudad, este cambio social apenas ha ejercido influencia sobre los valores sociales en los que tradicionalmente era socializada la mujer y menos sobre el prestigio social inferior al varón que hemos visto que se le concedía. La ideología masculina sigue considerando natural que sea la mujer quien cuide a los hijos y quien se encarga de realizar los trabajos domésticos, aunque ha tenido que integrar en sus esquemas tradicionales la incorporación del hombre a las tareas agrícolas tras la introducción de la moderna maquinaria agrícola (nuevo signo de prestigio, factor decisivo de la menor participación de la mujer en ellas), y las mujeres son, quizás, quienes parecen haber interiorizado ésta con más fuerza, como se ve por testimonios como éste: "son tan ricas, tan finas, tan cual..., pois xa non fan nada, o saber no ocupa lugar, hacer unha cama, barrer, fregar, facer todo como unha muller, anque seas estudiante; mañá te casas, tés un filo e tés que poñerlle o pañal e facer todo". El hecho reciente de que las jóvenes estudien e intenten incorporarse al mundo laboral no ha sido integrado, como puede verse, por la mujer adulta, que sigue manteniendo y contribuyendo a reproducir los valores (limpieza, casa, etc.) en los que fueron educadas. Y, en relación a la falta de control de la conducta sexual de la mujer, que antes puse en relación con el concepto cultural "naturaleza", acusan a las jóvenes de hoy de "desvergüenza" porque están fuera del ámbito (la casa) donde resultaría fácil controlarlas y a veces se conducen de un modo que les hace exclamar a las mujeres adultas: "ás veces me dou media volta e me largo por non velas, dame máis apuro a min que a elas".

\section{CONCLUSIONES}

Que la mujer (soltera o casada) recibe poca valoración en la familia por su contribución a la subsistencia de ésta espero que haya sido evidente por el análisis de los tipos de residencia post-matrimonial posibles y de la ritualización de la petición de mano y de la ceremonia nupcial en cada uno de ellos, así como de los motivos por los que la mujer prefiere el tipo de residencia post-matrimonial que le confiere menor valor social desde el punto de vista de la ideología masculina dominante. Que el valor social de la mujer está en función del de su unidad doméstica y del varón de más prestigio en ella, y que la deseabilidad de evitar una relación asimétrica hace que el hombre no desee casarse con mujeres de menor prestigio que él, aunque la mujer sí puede casarse con un hombre de prestigio inferior al suyo con tal que se ajuste al prototipo del "labrador", espero que haya sido evidente por el análisis de los juicios sociocéntricos que determinan 
el sistema de casamientos vigente hasta hace muy poco en esta zona. Pero sobre todo, espero haya sido evidente la asociación de la mujer con el concepto cultural de "naturaleza", que consideré en el apartado 3 y que intenté mostrar que estaba presente en ciertas actividades ritualizadas de la vida cotidiana campesina, en un "rito de inversión de status" y en el folclore de la zona; esta asociación la condena a ser inferiormente valorada siempre al hombre y a ocupar una posición inferior a éste en la jerarquía de prestigio social y no únicamente en el ritual. La potencia de la ideología masculina se demuestra, por tanto, en tres diferentes ámbitos de la sociedad tomada como un todo: la familia, la parroquia y el municipio, y se refleja ritualmente. Una interpretación semejante a la que se hizo en el apartado 3 en relación a la "malla" y a la matanza se puede encontrar en Brandes (1980) y algo más desarrollada en Frigolé (1987), en relación al área denominada "mediterránea" del sur de Europa. En relación a Galicia, Lourdes Méndez analizó la casa-edificio como un espacio alejado de "los territorios donde se ejerce el poder real" (espacio público) dentro de la explotación agrícola $(1988,208)$; en este sentido, la reclusión (y asociación "natural" consiguiente entre ambas) de la mujer en la casa-edificio posibilita el control socialmente ejercido sobre la primera que dije que estaba determinado por la asociación de la mujer con la "naturaleza", que la "cultura" considera necesario controlar para extraer algún provecho de ella. Se cierra, así, el círculo que abrimos con el apartado 1 . 


\section{BIBLIOGRAFÍA}

Brandes, S.: Metaphors of masculinity, Pennsylvania University Press, Pennsylvania, 1980.

Figolé Reixach, J.: "Metáforas domésticas y culinarias sobre la mujer en el área mediterránea", Reis, no 4, año 1987, 135-157.

Geertz, C.: La interpretación de las culturas, Gedisa, Barcelona, 1988.

Levi-Strauss, C.: Las estructuras elementales del parentesco, S. XXI, Méjico, 1967.

Lisón Tolosana, C.: Antropología cultural de Galicia, Ảkal, Madrid, 1970.

Méndez, L.: "Cousas de mulleres": campesinas, poder y vida cotidiana, (Lugo, 19401980), Anthropos, Barcelona, 1988.

Ortner, S.: "¿Es la mujer respecto del hombre lo que la naturaleza con respecto a la cultura?", en Antropología y feminismo, Anagrama, Barcelona, 1979.

Pitt-Rivers, J.: Antropología del honor o la política de los sexos, Alianza Editorial, 1984.

Un pueblo de la sierra, Grazalema, Alianza Editorial, 1988.

Tenorio, N.: La aldea gallega, Prim. edic. 1914 (1984).

Turner, V., El proceso ritual, Taurus, Madrid, 1988. 